\title{
Reduced graphene oxide modified with silver nanoparticles for the electrochemical detection of estriol
}

\author{
Caruane Alves Donini, Martin Kássio Leme da Silva, Rafael Plana Simões, Ivana Cesarino* \\ Sao Paulo State University (UNESP), School of Agriculture, Botucatu, SP, Brazil
}

\section{A R T I C L E I N F O}

\section{Keywords:}

Estriol

Oxidation mechanisms

Graphene, silver nanoparticles

Fukui indexes

\begin{abstract}
A B S T R A C T
This work presents the development of a sensor based on reduced graphene oxide (rGO) modified with silver nanoparticles (AgNPs) for the oxidation of estriol hormone. The morphology and electrochemical behavior of the rGO-AgNPs composite was characterized by scanning electron microscopy and cyclic voltammetry, demonstrating that the AgNPs were incorporated into rGO. The transfer of an electron from the estriol molecule for the working electrode at $+0.45 \mathrm{~V}$, and the consequent loss of an $\mathrm{H}^{+}$ion for the buffer solution was confirmed combining electrochemical experiments and molecular modelling techniques. The glassy carbon (GC) electrode modified with the rGO/AgNPs composite was optimized for the determination of estriol using differential pulse voltammetry (DPV), achieving detection limit of $21.0 \mathrm{nmol} \mathrm{L}^{-1}$ for estriol hormone. Reproducibility and repeatability values of $1.5 \%$ and $1.3 \%$, respectively, were obtained compared to the conventional procedure. The proposed GC/rGO-AgNPs electrochemical device was successfully applied to the determination of estriol in tap water and synthetic urine samples.
\end{abstract}

\section{Introduction}

Graphene, since its discovery in 2004, is one of the most widely used materials in electrochemistry, especially in the development of electrochemical devices, due to its extensive variety of mechanical, thermal [1], electronic [2], optical and phonon properties [3-5]. Furthermore, this molecule has the structure of a crystal lattice, hexagonal and planar, that offers a high electronic motility, a large specific surface area and extraordinary electrocatalytic activities $[4,6]$. The modification of graphene with metallic nanoparticles has been studied and applied for detection of several environmental pollutants, such as sulfamethoxazole [7] (SMX), trimethoprim [8] (TMP) and sulfamethazine (SMZ) [9]. Also, endocrine disruptors, for example, tryptophan [10] and $\beta$-estradiol [11] have been target analytes in electroanalytical chemistry.

Different metallic nanoparticles (MNPs), such as palladium [12,13], antimony [14-16], silver [17-19] and gold [20,21] are extensively used in electroanalysis, due to their good conductivity, high surface area [7], high chemical stability, tunable surface chemistry and comparatively low-cost [24]. The modification of carbon based material as carbon nanotubes [22,23] and graphene oxide [5], with MNPs are widely explored in electroanalysis. Among these MNPs are the silver nanoparticles (AgNPs) that display excellent antibacterial, electrical, optical, catalytic and surface-enhanced Raman properties [25]. Because of these properties, the AgNPs are used in sensors [8], spectroscopy [26] antibacterial materials [27] and to improve the performance of photovoltaic materials [28].

Steroid hormones are generally synthesized from cholesterol and include androgens, estrogens, glucocorticoids and progestogens. Estriol $(1,3,5,(10)$-estratriene-3,16 $\alpha, 17 \beta$-triol) can be found in pregnant mammals and is one of the essential phenolic estrogen hormone to the woman body, important in menstrual and reproductive cycles. This drug is mainly used in the treatment of urogenital diseases in menopausal women and in contraceptive pills, and is usually excreted in the urine of this patients. This estriol will subsequently enter waterways and cause major problem in water supplies, because its degradation is not completely during the water treatment [29-32].

Estriol is found as a water pollutant and can cause adverse effects by interfering with the function of hormones in human body, it belongs to the so called endocrine disrupting compounds group that has becoming a potential environmental risk [33]. Therefore, the determination of estriol at low concentrations is very important as well as the development of modern strategies of analysis. Actually, the determination of this hormone has been performed using electrophoresis [34], immunoassays [35], chromatographic techniques [36] and electroanalytical methods [37]. Among these, the last method is of great interest due to its operational simplicity, high sensitivity, fast response, low expense and potentiality for automation.

\footnotetext{
* Corresponding author.

E-mail address: ivana@fca.unesp.br (I. Cesarino).
} 
In this report, reduced graphene oxide (rGO) was modified with silver nanoparticles (AgNPs) for the determination of estriol hormone in tap water samples. The oxidation mechanism of estriol was proposed combining electrochemical experiments and molecular modelling analysis. The proposed electrochemical device offers a new tool for electroanalysis of endocrine disruptors.

\section{Experimental}

\subsection{Apparatus and procedures}

The electrochemical experiments of differential pulse voltammetry (DPV) and cyclic voltammetry (CV) were performed using a PGSTAT128N Autolab electrochemical system (Metrohm) equipped with Nova 2.0 software (Metrohm). The cell was assembled with a conventional three-electrode electrochemical system: bare GC, GC/rGO or $\mathrm{GC} / \mathrm{rGO}-\mathrm{AgNPs}$ as a working electrode (diameter: $3 \mathrm{~mm}$ ); $\mathrm{Ag} / \mathrm{AgCl}$ / $\mathrm{KCl}\left(3.0 \mathrm{~mol} \mathrm{~L}^{-1}\right)$ as a reference electrode; and a Pt plate as an auxiliary electrode. All experiments were carried out at a controlled temperature $\left(25 \pm 1{ }^{\circ} \mathrm{C}\right)$. Electrochemical characterization of the electrodes, were performed by using $\mathrm{CV}$ in a $0.2 \mathrm{~mol} \mathrm{~L}^{-1}$ phosphate buffer solution (PBS) with a scan rate of $50 \mathrm{mV} \mathrm{s}^{-1}$. DPV measurements were obtained with a scan rate of $10 \mathrm{mV} \mathrm{s}^{-1}$, pulse amplitude of $100 \mathrm{mV}$, and a step potential of $5 \mathrm{mV}$ in $0.2 \mathrm{~mol} \mathrm{~L}^{-1} \mathrm{PBS} \mathrm{pH}$ 8.0.

The morphology of rGO and the rGO-AgNPs composite was characterized using field-emission gun-scanning electron microscopy (FEGSEM) and the images were recorded using a model FEI Inspect F50 microscope (FEI Company, Hillsboro, USA).

\subsection{Reagents and solutions}

All reagents used in this research were analytical grade and were used without further purification treatment. All the solutions were prepared with water purified in a Millipore Milli-Q system with a resistivity $\geq 18 \mathrm{M} \Omega \mathrm{cm}$. A solution of alumina $0.3 \mu \mathrm{m}$ was used to polish the glassy carbon electrodes. Potassium phosphate (Dinamica Brazil) was used to prepare all buffer solutions (PBS). Estriol and graphene oxide (GO) were obtained from Sigma-Aldrich (Germany).

\subsection{Synthesis of rGO and rGO-AgNPs composite}

The rGO-AgNPs composite was synthesized using sodium dodecyl sulphate (SDS) as a surfactant. A ratio by weight of 10:4 GO/SDS (20 mg of GO: $8 \mathrm{mg}$ of SDS) was dissolved in $15 \mathrm{~mL}$ of ethanol (pure grade) and then the suspension was sonicated for $20 \mathrm{~min}$. An amount of $13 \mathrm{mg}$ of sodium borohydride was then added, and this suspension was sonicated for another $20 \mathrm{~min}$. A $5 \mathrm{~mL}$ solution containing $4 \mathrm{mg}$ of $\mathrm{AgNO}_{3}(20 \%$ in relation to the amount of GO) was slowly dropped into the rGO solution, which was kept under constant stirring. Once the reaction was complete, the rGO-AgNPs composite was dispersed using an ultrasonic probe for $1 \mathrm{~h}$. The rGO-AgNPs obtained were centrifuged for $5 \mathrm{~min}$ at $3000 \mathrm{rpm}$ and washed several times with ethanol pure grade until the solution became colorless. After that, $5 \mathrm{~mL}$ of ethanol (pure grade) was added to the resulting composite and then the rGOAgNPs were dried at $60^{\circ} \mathrm{C}$.

The chemical synthesis of rGO was also performed, but without adding $\mathrm{AgNO}_{3}$, to evaluate the synergistic effect of rGO and AgNPs.

\subsection{Electrodes preparation}

Prior to the modification of the GC electrodes, the surface was polished with $0.3 \mu \mathrm{m}$ alumina slurries, rinsed thoroughly with doubledistilled water, sonicated for $5 \mathrm{~min}$ in ethanol afterwards $5 \mathrm{~min}$ in water and subsequently air dried. A suspension containing $0.025 \mathrm{mg}$ of rGO$\mathrm{AgNPs}$ composite and $1 \mathrm{~mL}$ of water was dispersed using ultrasonic stirring for $20 \mathrm{~min}$. A $10 \mu \mathrm{L}$ aliquot of the rGO-AgNPs composite dispersion was dropped onto the GC electrode surface and dried at room temperature. For comparison, the $\mathrm{GC} / \mathrm{rGO}$ electrode was also prepared as described above, but using $0.025 \mathrm{mg}$ of rGO and $1 \mathrm{~mL}$ of water to prepare the suspension.

\subsection{Theoretical analysis}

For the first geometry optimization, 100 conformers of estriol structure were obtained from the molecular dynamics (MD) simulations at temperature of $1000 \mathrm{~K}$ using Steepesp Descent method and the Verlet algorithm. The time of simulation was $10 \mathrm{~ns}$ with step size of $1 \mathrm{fs}$. The MD simulation and analysis were performed using the Gabedit computational package [38].

All conformers were then pre-optimized via the PM6 semi-empirical method in a Hartree-Fock (HF) approach with the aid of the MOPAC2016 computational package [39]. The presence of the solvent was simulated via the Conductor-like Screening Model-COSMO (with $\varepsilon=80.1$ ). After pre-optimizations, the most stable conformer was fully optimized via Density Functional Theory (DFT) calculations. Becke's LYP (B3LYP) exchange-correlation functional and 6-31G(p,d) basis set were employed. The Polarizable Continuum Model (PCM) was employed for simulating the presence of the solvent at this stage [9].

The structure with lowest conformational energy was used as input for a new step of MD simulation, but, this time at constant temperature of $300 \mathrm{~K} .100$ new conformers were obtained from this simulation and their electronic properties were newly determined via DFT calculations. The objective of this MD step was to determine the average values for the highest occupied molecular orbital (HOMO) of the estriol molecule under temperature similar to the experimental conditions.

The evaluation of molecular reactivity was accomplished by Condensed-to-Atoms Fukui Indexes (CAFIs). The three distinct CAFIs can be defined as:

$f_{k}^{+}=q_{k}(N+1)-q_{k}(N)$ for nucleophilic attack on atom $k$

$f_{k}^{-}=q_{k}(N)-q_{k}(N-1)$ for electrophilic attack on atom $k$

$f_{k}^{0}=1 / 2\left[q_{k}(N+1)-q_{k}(N-1)\right]$ for radical attack on atom $k$

where $q_{k}(N+1), q_{k}(N)$ and $q_{k}(N-1)$ represent, respectively, the electronic population on the $k$-th atom of anionic, cationic and neutral species of the studied compound [9].

All the DFT calculations were performed with the aid of the Gaussian 09 computational package [40].

\subsection{Sample preparation and analysis of estriol in natural water an synthetic} urine

The synthetic urine was prepared by a procedure similar to that described by Laube et al. [41]. The solution components are $1.10 \mathrm{~g}$ of $\mathrm{CaCl}_{2} \cdot 2 \mathrm{H}_{2} \mathrm{O}, 2.92 \mathrm{~g}$ of $\mathrm{NaCl}, 2.25 \mathrm{~g}$ of $\mathrm{Na}_{2} \mathrm{SO}_{4}, 1.40 \mathrm{~g}$ of $\mathrm{KH}_{2} \mathrm{PO}_{4}, 1.60 \mathrm{~g}$ of $\mathrm{KCl}, 1.00 \mathrm{~g}$ of $\mathrm{NH}_{4} \mathrm{Cl}, 25.00 \mathrm{~g}$ of urea, and $1.10 \mathrm{~g}$ of creatine at $\mathrm{pH} 7.0$ per liter of ultrapure water. Known amounts of the standard estriol solution were added to a $10.0 \mathrm{~mL}$ aliquot of tap water or synthetic urine mixed with $10.0 \mathrm{~mL}$ of $0.2 \mathrm{~mol} \mathrm{~L}^{-1} \mathrm{PBS} \mathrm{pH} 8.0$, giving a final concentration of $0.5 \mu \mathrm{mol} \mathrm{L}^{-1}$ estriol. No additional sample treatment was done. The estriol content was determined by three successive additions of aliquots of the standard estriol solution.

\section{Results and discussions}

\subsection{Surface morphology and electrochemical characterization of the rGO- AgNPs composite}

The surface morphology of the rGO and rGO-AgNPs composite samples was characterized by FEG-SEM. A drop of ethanolic suspension of these materials was applied onto the Si substrate and the SEM micrographs of rGO and rGO-AgNPs are shown in Fig. 1. Fig. 1A exhibits 

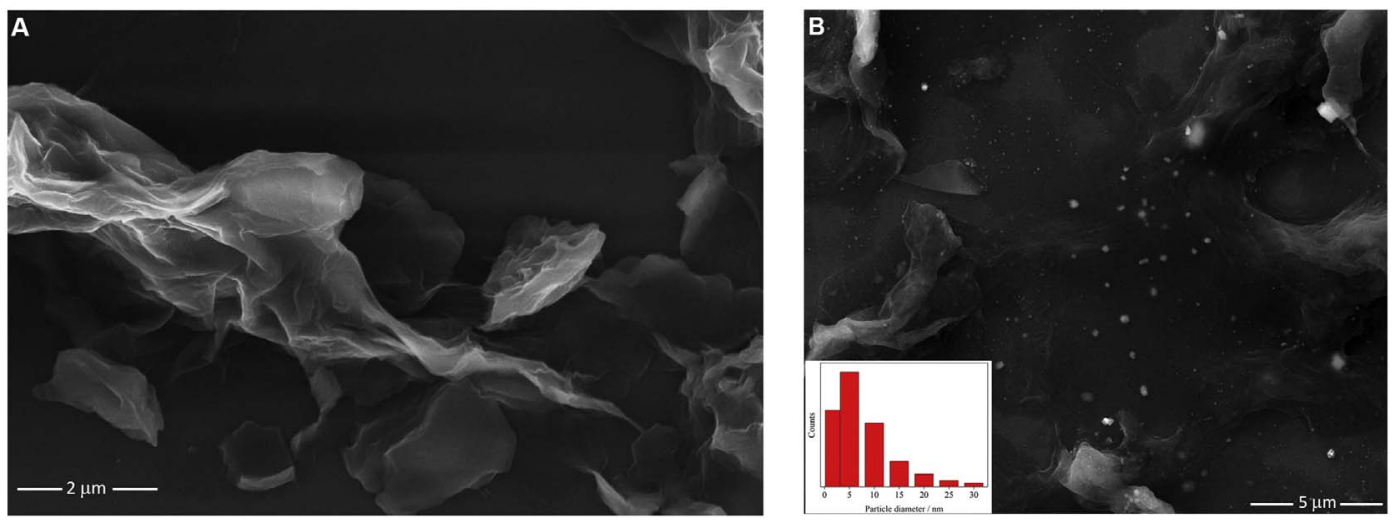

Fig. 1. FEG-SEM micrographs for (A) rGO and (B) rGO-AgNPs composite.

the images of $\mathrm{rGO}$, in which the graphitic material display a twisted structure due the chemical reduction of GO, presenting abundant structural defects. On the other hand, Fig. 1B shows images of the rGO-AgNPs composites, in which it is possible to observe that the rGO was modified with a large number of $\mathrm{Ag}$ nanoparticles. When the AgNPs are incorporated, there is an increase in the availability of these catalytic sites in the surface area of the electrode. It is also possible to observe that the AgNPs are well dispersed in the rGO sheets and have sizes varying between 2 and $30 \mathrm{~nm}$, in which the major counts of particles have a size varying between 2 and $10 \mathrm{~nm}$, as showed in histogram inset on Fig. 1B.

The electrochemical characterization was also performed to confirm the presence of $\mathrm{Ag}$ nanoparticles. $\mathrm{CV}$ experiments were carried out in $0.2 \mathrm{~mol} \mathrm{~L}^{-1}$ of $\mathrm{NaNO}_{3}$ solution with a scan rate of $50 \mathrm{mV} \mathrm{s}^{-1}$ for the electrodes as presented in Fig. 2. The electrochemical behavior of the GC electrode modified with the rGO-AgNPs composite was compared with the voltammetric response of the GC/rGO electrode. Using the GC/ rGO electrode (curve a) no electrochemical process was observed. However, the GC electrode modified with the rGO-AgNPs composite presented a peak at $+0.39 \mathrm{~V}$, which corresponds to the oxidation of $\mathrm{Ag}^{0}$ to $\mathrm{Ag}^{+}$. A quase-reversible process at $+0.15 \mathrm{~V}$, corresponding to the reduction of $\mathrm{Ag}^{+}$was also observed. These electrochemical processes for the Ag peaks on the electrode surface are consistent with other studies described in the literature $[8,18]$.

\subsection{Electrochemical behavior of GC/rGO-AgNPs composite electrode on the estriol oxidation process}

Cyclic voltammetry experiments in $0.2 \mathrm{~mol} \mathrm{~L}^{-1} \mathrm{PBS} \mathrm{pH} 9.0$, containing $50.0 \mu \mathrm{mol} \mathrm{L}^{-1}$ were carried out to evaluate the electrochemical

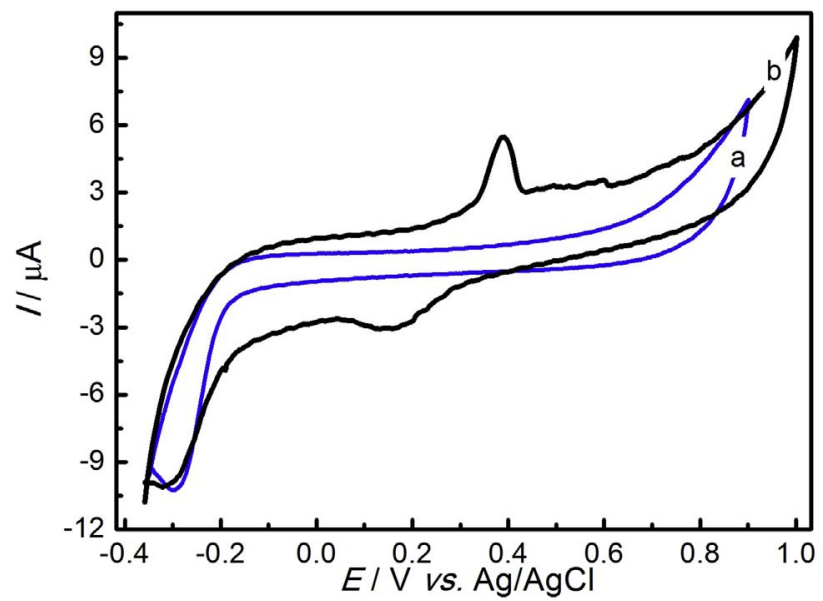

Fig. 2. Cyclic voltammetry characterization in $0.2 \mathrm{~mol} \mathrm{~L}^{-1}$ of $\mathrm{NaNO}_{3}$ solution with a scan rate of $50 \mathrm{mV} \mathrm{s}^{-1}$ for the (a) GC/rGO and (b) GC/rGO-AgNPs composite electrodes.

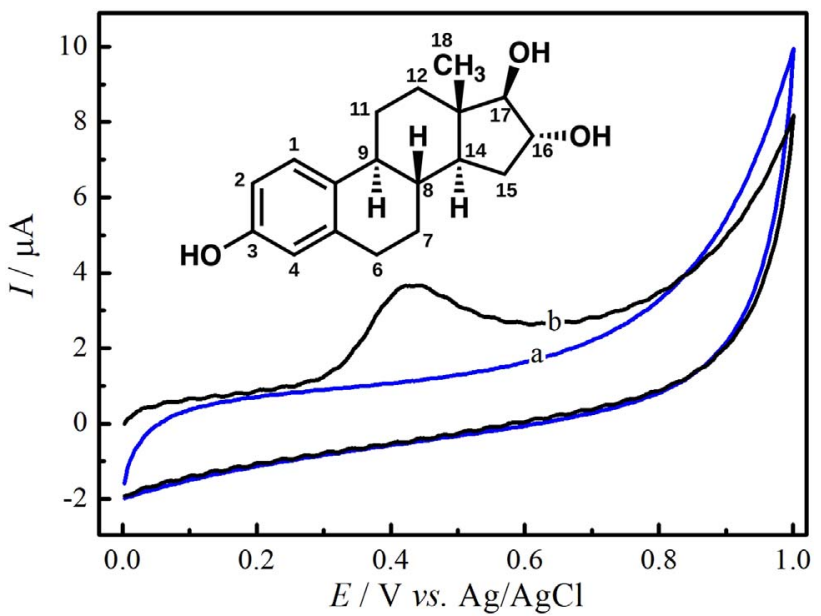

Fig. 3. CV scans of the GC/rGO-AgNPs composite electrode in $0.2 \mathrm{~mol} \mathrm{~L}^{-1} \mathrm{PBS} \mathrm{pH} 9.0$ in the absence (curve a) and in the presence (curve b) of $50.0 \mu \mathrm{mol} \mathrm{L}^{-1}$ of estriol with a scan rate of $50 \mathrm{mV} \mathrm{s}^{-1}$. Inset: Bi-dimensional representation of the estriol molecule [41].

behavior of the estriol oxidation process on the GC/rGO-AgNPs composite electrode, with a scan rate of $50 \mathrm{mV} \mathrm{s}^{-1}$. The voltammograms are shown in Fig. 3 and the inset presents a 2D illustration of the estriol molecule, where each carbon atom was numbered to guide the analysis that will discussion in Section 3.3. In the absence of estriol (curve a), no electrochemical process was observed. Therefore, when estriol was added in the solution (curve b) a well-defined irreversible oxidation peak at $+0.45 \mathrm{~V}$ was presented corresponding to the oxidation of the phenolic hydroxyl group.

The DPV experiments were also performed using the GC, GC/rGO and GC/rGO-AgNPs electrodes, to evaluate the increase on the anodic peak current for estriol. The range of the potential was from 0.0 to $+1.0 \mathrm{~V}$ vs. $\mathrm{Ag} / \mathrm{AgCl} / \mathrm{KCl}\left(3.0 \mathrm{~mol} \mathrm{~L}^{-1}\right)$ in $0.2 \mathrm{~mol} \mathrm{~L}^{-1} \mathrm{PBS}$ at $\mathrm{pH} 9.0$ containing $2.5 \mu \mathrm{mol} \mathrm{L}^{-1}$ estriol (Figure not shown). The voltammetric profiles had peaks at almost identical potentials of approximately $+0.45 \mathrm{~V}$ vs. $\mathrm{Ag} / \mathrm{AgCl} / \mathrm{KCl}\left(3.0 \mathrm{~mol} \mathrm{~L}^{-1}\right)$ for all electrodes studied. However, the GC/rGO-AgNPs electrode displayed higher anodic current intensity for estriol in comparison with the current observed for the other electrodes. An increase by a factor of 1.5 and 1.2 in the anodic peak current of estriol was observed when compared the $\mathrm{CG} / \mathrm{rGO}$ AgNPs electrode to the GC and GC/rGO electrodes, respectively. The higher oxidation peak currents for estriol was due the structural defects of rGO combined with the synergistic properties of silver nanoparticles.

In order to provide the mechanism of estriol oxidation on the $\mathrm{GC}$ / rGO-AgNPs composite electrode, the dependence of the estriol oxidation process on $\mathrm{pH}$ was also studied using DPV experiments containing $50.0 \mu \mathrm{mol} \mathrm{L}^{-1}$ at pHs on range from 5.0 to 10.0, as presented in Fig. 4. When analyzing the dependence of the peak potential for estriol 


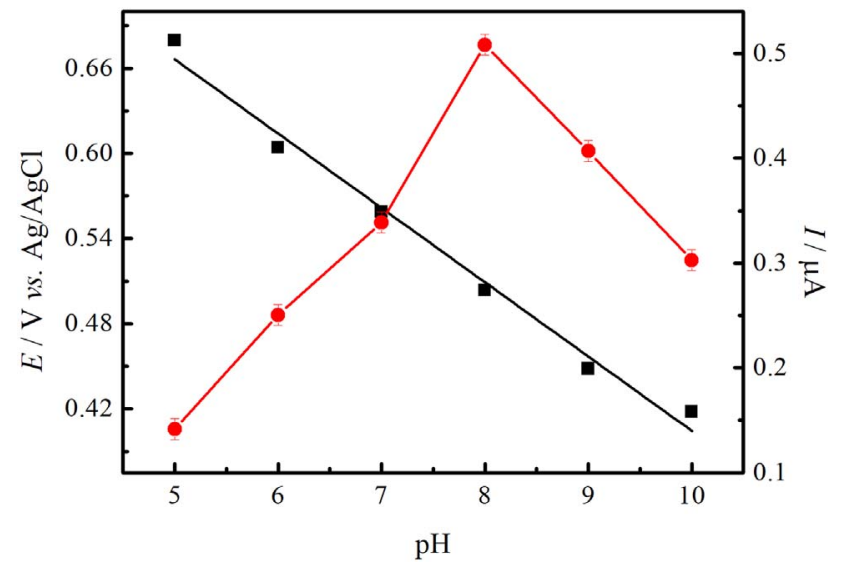

Fig. 4. Effect of $\mathrm{pH}$ on the peak potential $(\boldsymbol{\square})$ and peak current $(\bullet)$ for estriol oxidation on the GC/rGO-AgNPs composite electrode using $0.2 \mathrm{~mol} \mathrm{~L}^{-1}$ PBS containing $50.0 \mu \mathrm{mol} \mathrm{L}^{-1}$ of estriol.

oxidation on different $\mathrm{pHs}$, it was observed a linear relationship, with a slope of $52 \mathrm{mV}$ per $\mathrm{pH}$ unit. The hydrogen ionic concentration reduction of the electrolyte causes a shift in peak potential for estriol oxidation towards more negative values. This is a consequence of deprotonation during the oxidation process, which is facilitated at higher $\mathrm{pH}$. Therefore, the electrochemical process involves the same number of protons and electrons during the electrooxidation of estriol, which is typical behavior for the oxidation of phenols. For further comprehension of the oxidation process of estriol, molecular modelling techniques were studied.

\subsection{Theoretical analysis}

Fig. 5A presents the 3D structure of the conformation of minimal energy obtained for the estriol molecule and Fig. 5B shows the CAFIs of the estriol. This result suggest the $\mathrm{O}$ atom of hydroxyl group bonded to the C3 (inset Fig. 3) atom is more susceptible to an electrophilic attack, denoted by the $f^{-}$indices, i.e. the molecular site that is prone to undergo oxidation processes experimentally observed. This affirmation is confirmed by examining the location of the HOMO represented in the Fig. 5C, which is distributed under the referred $\mathrm{O}$ atom and the aromatic ring formed by the C1-C5 and C10 atoms (inset Fig. 3), due the resonance effect of the double bonds in this ring. These results are compatible with previous theoretical study (also applying a DFT approach) that analyzed the properties and degradation of natural estrogen hormones with chemical oxidizers [42].

The difference between the average value of the HOMO energy levels for the sample of estriol at $300 \mathrm{~K}(\sim-5.60 \mathrm{eV})$ and the work function of the rGO/AgNPs electrode (from $-5.17 \mathrm{eV}$ until $-4.96 \mathrm{eV}$ ) also is compatible with the potential of the oxidation peak observed in our electrochemical results. The experiments shown that oxidation peak occurs at $+0.45 \mathrm{eV}$, which allows the electron transition from the estriol HOMO to the working electrode. The Fig. 6 present an illustration of this transition. It should be noted that the HOMO energy level

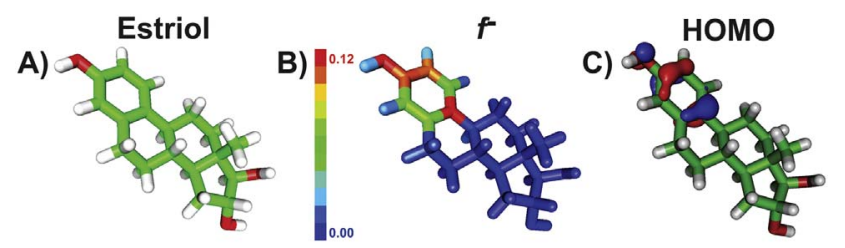

Fig. 5. Representation of: (A) 3D estriol structure; (B) $f^{-}$from CAFI values, where red and blue regions indicate very reactive and non-reactive sites, respectively and; (C) location of the HOMO. (For interpretation of the references to colour in this figure legend, the reader is referred to the web version of this article.)

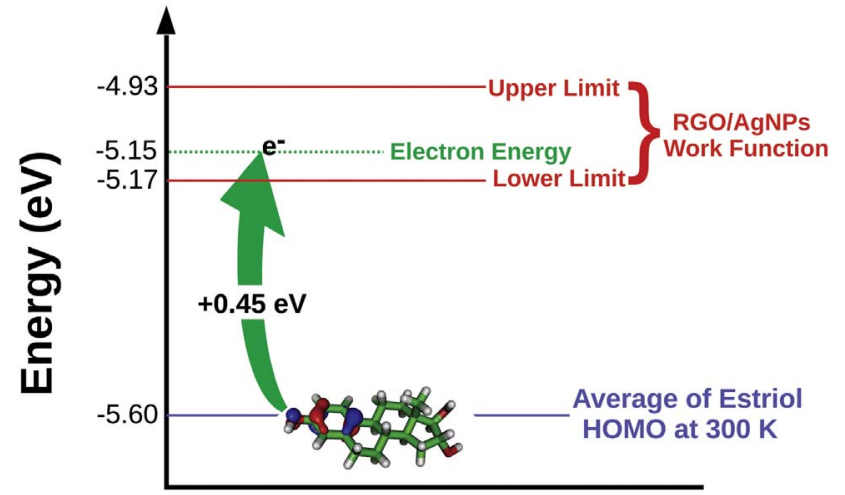

Fig. 6. Illustration of the electronic transition from the estriol HOMO to the rGO/AgNPs The green arrow represents the oxidation energy observed on the electrochemical experiments. (For interpretation of the references to colour in this figure legend, the reader is referred to the web version of this article.)

presented in the Fig. 6 corresponds to the average HOMO energy for all structures obtained from the MD simulations at temperature of $300 \mathrm{~K}$. The values of work function of the rGO/AgNPs were obtained from the literature, in which a large range of values are related, depending of the Ag nanoparticles size and concentration [43-47].

As consequence of the loss of one electron, the $\mathrm{O}$ atom of the hydroxyl group on the $\mathrm{C} 3$ became very susceptible to a nucleophilic attack, since it present sites with high $f^{+}$values, as can be seen on the Fig. 7, which presents the CAFIs of the estriol molecule with positive liquid charge after the oxidation process. Obviously, this result is very similar to the $f^{-}$values of the estriol in its fundamental state, and it indicates this $\mathrm{O}$ atom is the most reactive for reactions towards nucleophilic agents, suggesting that $\mathrm{OH}^{-}$ions from PBS could attack this region generating an estriol protolytic specie. It should be highlighted from this result that, besides the $\mathrm{C} 2$, C3 and $\mathrm{C} 10$ atoms also present high $f^{+}$values, they are more stable than the $\mathrm{O}$ atom because they are part of the structure of the aromatic ring.

In this way, all these results indicate the mechanism of estriol oxidation, which is given by the losing of one electron and one $\mathrm{H}^{+}$ion. This EC process is compatible with was predicted by the Nernst Equation in our systems. As consequence of the oxidation process, the simple bond between the $\mathrm{O}$ and $\mathrm{C} 3$ atoms becomes a double bond, altering the distribution of the double bonds (and the resonance effect) on the aromatic ring and stabilizing the molecule. The Fig. 8 synthetizes this molecular oxidation mechanism. The stable state of the estriol protolytic specie makes the oxidation process irreversible, which corroborates with the experimental results where it is observed a reduction peak for negative potentials.

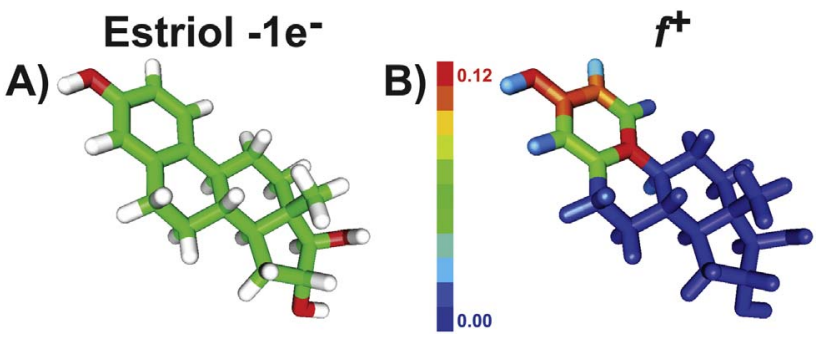

Fig. 7. Representation of: (A) 3D estriol structure after to loser one electron and; (B) $f^{+}$ from CAFI values, where red and blue regions indicate very reactive and non-reactive sites, respectively. (For interpretation of the references to colour in this figure legend, the reader is referred to the web version of this article.) 
<smiles>CC12CCc3cc(O)ccc3C1CCC1(C)C(O)[C@@H](O)CC21</smiles><smiles>CC12CCC3C4C=CC(=O)C=C4CC[C@H]3[C@@H]1C[C@H](O)C2O</smiles>

Fig. 8. Oxidation mechanism for the estriol in the electrochemical experiments.

3.4. Parameters for the optimization of the estriol voltammetric response on the GC/rGO-AgNPs composite electrode

According to Fig. 4, the following experiments were performed in $0.2 \mathrm{~mol} \mathrm{~L}^{-1} \mathrm{PBS} \mathrm{pH} 8.0$ because in this $\mathrm{pH}$ was observed the highest anodic peak current. DPV experiments was conducted containing $10.0 \mu \mathrm{mol} \mathrm{L}^{-1}$ estriol. The first optimized parameter was rGO-AgNPs composite amounts in the preparation of the sensor. The quantities of rGO-AgNPs studied were 0.012, 0.025, 0.050, 0.075 and $0.100 \mathrm{mg} \mathrm{mL}^{-1}$. The highest anodic peak current was observed when $10 \mu \mathrm{L}$ of a suspension containing $0.025 \mathrm{mg} \mathrm{mL}^{-1}$ of rGO-AgNPs was used in the preparation of the sensor as showed in Fig. 9A. Then, this amount of the composite was used in the further experiments.

We next investigated the influence of the composition of the electrode material. In these experiments, the amount of GO was fixed and the quantity of $\mathrm{AgNO}_{3}$ was varied in the following proportions: $10 \%$, $20 \%, 25 \%$ and $30 \%(w / w)$. In Fig. 9B, it was observed that the anodic peak current increased with the amount of $\mathrm{AgNO}_{3}$ in the composite up to $20 \%(\mathrm{w} / \mathrm{w})$, then decreased when a higher amount of $\mathrm{AgNO}_{3}$ was used. This behavior is probably due to the formation of clusters of AgNPs when a higher quantity of $\mathrm{AgNO}_{3}$ is employed in the synthesis of the rGO-AgNPs composite. Based on these results, $20 \%(\mathrm{w} / \mathrm{w}) \mathrm{AgNO}_{3}$ was used in all the electrodes prepared for the estriol analysis.

Since the estriol or its oxidation products are likely to be adsorbed on the electrode surface, the pre-treatment potential study was also carried out. Pre-treatment potential values of $-0.2,-0.4,-0.6$, $-0.8,-1.0,-1.1$ and $-1.2 \mathrm{~V}$ were investigated with the pre-treatment time fixed at $30 \mathrm{~s}$. The anodic peak current for the estriol oxidation without the pre-treatment was lower than when these potential was applied. This indicates that the pre-treatment potential can concentrate the estriol molecules near the surface of the GC/rGO-AgNPs electrode, which provides a higher signal processing for the estriol oxidation. The highest oxidation process was obtained when the $-0.8 \mathrm{~V}$ potential was applied for $30 \mathrm{~s}$. Thus, for the following experiments a pre-treatment potential of $-0.8 \mathrm{~V}$ for $30 \mathrm{~s}$ was used.

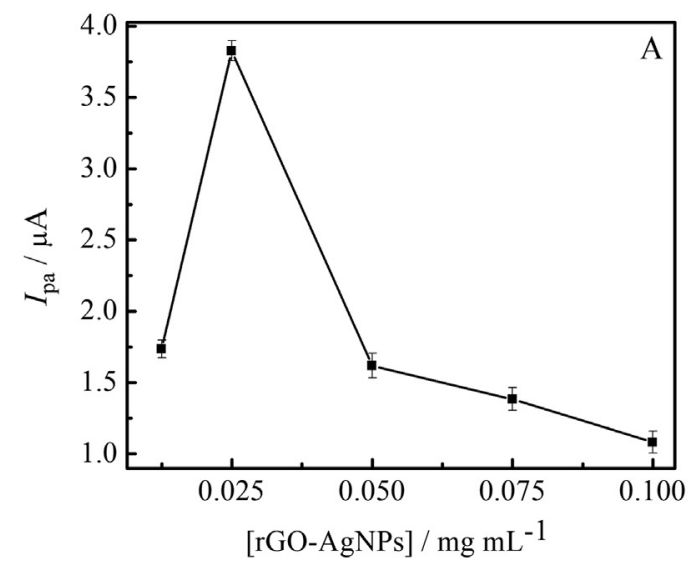

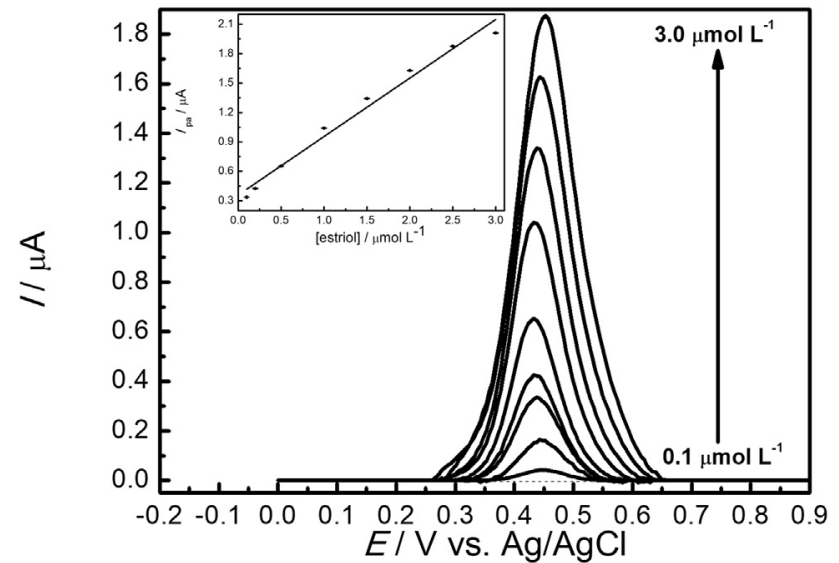

Fig. 10. DPV voltammograms for GC/rGO-AgNPs composite electrode, with the optimized parameters and in the range from 0.1 to $3.0 \mu \mathrm{mol} \mathrm{L}^{-1}$ of estriol concentrations. Inset: linear dependence of the peaks current with estriol concentrations.

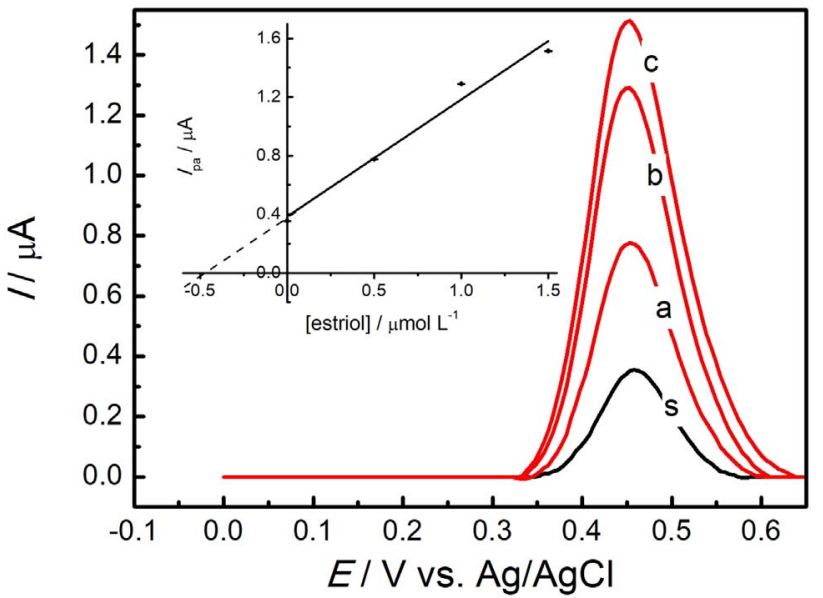

Fig. 11. DPV responses obtained on a GC/rGO-AgNPs sensor for the determination of estriol in tap water sample: S) sample; a) sample plus $0.5 \mu \mathrm{mol} \mathrm{L}^{-1}$ estriol; b) sample plus $1.0 \mu \mathrm{mol} \mathrm{L}^{-1}$ estriol; c) sample plus $1.5 \mu \mathrm{mol} \mathrm{L}^{-1}$ estriol. Inset: linear dependence of the peak current with estriol concentrations.

\subsection{Interferences}

When analyzing estriol in urine samples, some interferents such as uric acid (UA) and ascorbic acid (AA) can affect the precise

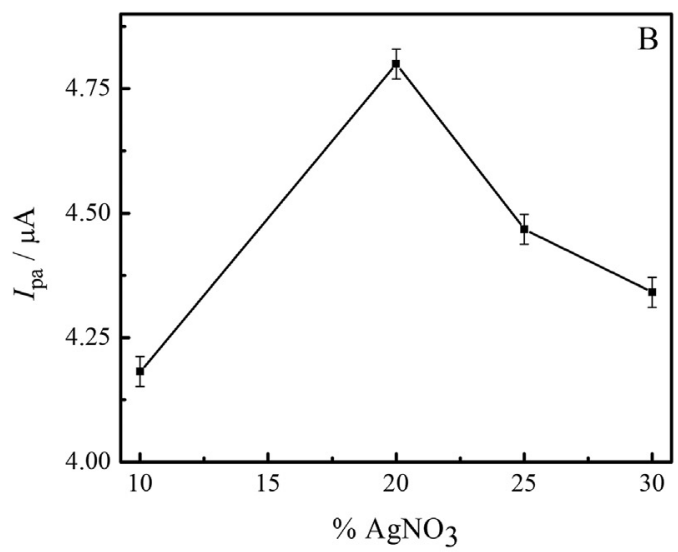

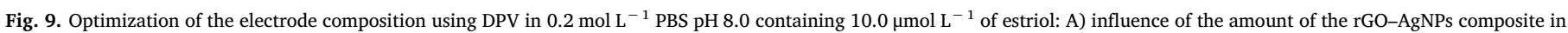
the electrode preparation and $\mathrm{B}$ ) influence of the $\mathrm{AgNO}_{3}$ percentage in the electrode preparation. 
Table 1

Results for the determination of estriol in tap water and synthetic urine samples by DPV proposed.

\begin{tabular}{llllll}
\hline \multirow{2}{*}{ Repetition } & \multicolumn{2}{l}{ Estriol $\left(\mu \mathrm{mol} \mathrm{L}{ }^{-1}\right)$} & & \multicolumn{2}{l}{ Relative errors (\%) } \\
\cline { 2 - 3 } \cline { 5 - 6 } \cline { 5 - 6 } & Tap water & Synthetic urine & & $\mathrm{E}_{1}$ & $\mathrm{E}_{2}$ \\
\hline & 0.482 & 0.474 & & -3.52 & -5.14 \\
2 & 0.541 & 0.464 & & 8.20 & -7.22 \\
3 & 0.540 & 0.453 & & 8.00 & -9.36 \\
Mean \pm SD & $0.521 \pm 0.027$ & $0.454 \pm 0.020$ & & \\
\hline
\end{tabular}

determination of this analyte. Therefore, we investigated the analytical performance of the rGO-AgNPs electrode using DPV experiments in the presence of such interferents. An overlap process between the estriol oxidation peak and the oxidation peak of the interfering substances studied was not observed. In addition, the interfering substances did not present an oxidation process in the potential range studied. The effect of $\mathrm{AA}$ and UA on the estriol anodic peak current was evaluated using $0.2 \mathrm{~mol} \mathrm{~L}^{-1}$ of PBS ( $\mathrm{pH} \mathrm{8.0)}$ containing a fixed concentration of $2.0 \mu \mathrm{mol} \mathrm{L}^{-1}$ of estriol and sequential additions of $1.0,2.0$ and $4.0 \mu \mathrm{mol} \mathrm{L}^{-1}$ of UA and AA. Recoveries of 98,101 , and $103 \%$ of dopamine $(n=3)$ were obtained when $1.0,2.0$, and $4.0 \mu \mathrm{mol} \mathrm{L}^{-1}$ of UA were added to each measurement, and recoveries of 91,99 , and $112 \%$ were obtained for AA, respectively. It is possible to observe that was no interference of UA and that the AA slightly interfered in the estriol determination. These interferences can be minimized using the standard addition method.

\subsection{Analytical characteristics}

DPV experiments were carried out in triplicate using the optimized experimental parameters to obtain an analytical curve for determination of estriol with the GC/rGO-AgNPs composite electrode. The analytical response shown in Fig. 10 has a linear response in the range 0.1 to $3.0 \mu \mathrm{mol} \mathrm{L}-1$, in agreement with the following equation:

$I_{p a}(\mu \mathrm{A})=0.35(\mu \mathrm{A})+0.59\left(\mu \mathrm{A} / \mu \mathrm{mol} \mathrm{L}^{-1}\right)[$ estriol $]\left(\mu \mathrm{mol} \mathrm{L}^{-1}\right)$

with a correlation coefficient of $0.980(n=9)$. The limit of detection (LOD) obtained was $21 \mathrm{nmol} \mathrm{L}^{-1}$, which was determined using a $3 \sigma /$ slope ratio, where $\sigma$ is the standard deviation of the mean value for 10 voltammograms of the blank.

Comparing the results of the GC/rGO-AgNPs with other electrochemical methods for estriol detection, a lower LOD of $0.5 \mathrm{nmol} \mathrm{L}^{-1}$ was observed using a GC/rGO-SbNPs electrode [4]. Ochiai et al. [48] found a higher LOD of $0.53 \mu \mathrm{mol} \mathrm{L} \mathrm{L}^{-1}$ using a screen-printed carbon electrodes modified with carbon nanotubes. A LOD of $0.79 \mathrm{ppm}$ was found using carbon paste electrode modified with ferrimagnetic nanoparticles [49]. A higher LOD of $1.7 \times 10^{-7} \mathrm{~mol} \mathrm{~L}^{-1}$ was observed using a boron-doped diamond electrode [50]. Lin et al. [37] also found a high LOD of $620 \mathrm{nmol} \mathrm{L}^{-1}$ using a GC electrode modified with Pt nano-clusters/multi-walled carbon nanotubes. Using an electrochemical immunoassay, a LOD of $0.33 \mathrm{ng} \mathrm{mL}^{-1}$ for estriol was determined [51], which is a higher value than the proposed electrochemical method.

The reproducibility of the GC/rGO-AgNPs electrode was measured from five experiments, in which each experiment consisted of ten sequential DPV voltammograms. These experiments were performed on different days. Prior to each experiment, the electrode surfaces were rinsed thoroughly with double-distilled water. Thus, the DPV voltammograms were performed in $0.2 \mathrm{~mol} \mathrm{~L}^{-1} \mathrm{PBS}$ at $\mathrm{pH} 8.0$ containing $1.0 \mu \mathrm{mol} \mathrm{L}^{-1}$ of estriol. The RSD was calculated as $1.5 \%$. In addition, intra-assay precision tests were performed from ten DPV voltammograms of that same solution. The RSD was found to be $1.3 \%$.

\subsection{Determination of estriol in tap water and synthetic urine}

In order to evaluate the proposed sensor in determination of estriol in tap water and synthetic urine samples, DPV experiments were performed and the obtained voltammograms using standard addition method are shown in Fig. 11. All analysis were conduct in triplicate and the samples were prepared as described in the experimental section. The results obtained (mean $\pm \mathrm{SD}$ ) for three determinations are presented in Table 1.

Estriol recoveries between $96.4 \%$ and $108.2 \%$ were obtained from tap water samples $(n=3)$ for samples spiked with $0.5,1.0$ and $1.5 \mu \mathrm{mol} \mathrm{L}^{-1}$ of estriol. For synthetic urine samples $(n=3)$, recoveries between $86.9 \%$ and $90.4 \%$ estriol were obtained for samples spiked with $0.5,1.0$ and $2.0 \mu \mathrm{mol} \mathrm{L}{ }^{-1}$ of estriol.

There were no significant differences between the found and added concentrations of estriol, indicating that the GC/rGO-AgNPs can be successfully used for the determination of estriol in natural water and urine samples under the optimized conditions and using the standard addition approach.

\section{Conclusions}

A synergistic combination of reduced graphene oxide and silver nanoparticles was used to develop a modified glassy carbon electrode, which was evaluated for the oxidation of estriol. The rGO-AgNPs were successfully characterized by FEG-SEM microscopy and electrochemically, which indicated that the GO was reduced and that the rGO was modified with the Ag nanoparticles.

The molecular oxidation mechanism for the estriol was explained combining electrochemical experiments and molecular modelling analysis. This mechanism consists of the transfer of an electron from the estriol molecule for the working electrode at $+0.45 \mathrm{~V}$, and the consequent loss of an $\mathrm{H}^{+}$ion for the buffer solution. This oxidation process makes the molecule stable and oxidation process irreversible.

The GC/rGO-AgNPs electrode was successfully applied for the determination of estriol hormone in tap water and synthetic urine samples, which presents as an alternative material for future applications in this area.

\section{Acknowledgments}

We are grateful for financial support from PROPe-UNESP (2016/ 37082) and FAPESP (2015/02136-2).

\section{References}

[1] G.L.C. Paulus, J.T. Nelson, K.Y. Lee, Q.H. Wang, N.F. Reuel, B.R. Grassbaugh, S. Kruss, M.P. Landry, J.W. Kang, E.V. Ende, J. Zhang, B. Mu, R.R. Dasari, C.F. Opel, K.D. Wittrup, M.S. Strano, A graphene-based physiometer array for the analysis of single biological cells, Sci. Rep. 4 (2014) 1.

[2] K. Kim, H. Lee, R.W. Johnson, J.T. Tanskanen, N. Liu, M.G. Kim, C. Pang, C. Ahn, S.F. Bent, Z. Bao, Selective metal deposition at graphene line defects by atomic layer deposition, Nat. Commun. 5 (2014) 1-9.

[3] A.K. Geim, Graphene: status and prospects, Science 324 (2009) 1530.

[4] I. Cesarino, F.H. Cincotto, S.A.S. Machado, A synergistic combination of reduced graphene oxide and antimony nanoparticles for estriol hormone detection, Sensors Actuators B Chem. 210 (2015) 453.

[5] R. Raccichini, A. Varzi, S. Passerini, B. Scrosati, The role of graphene for electrochemical energy storage, Nat. Mater. 14 (2014) 1.

[6] C. Gao, X. Huang, Voltammetric determination of mercury(II), TrAC 51 (2013) 1.

[7] M. Shabani-Nooshabadi, M. Roostaee, Modification of carbon paste electrode with $\mathrm{NiO} /$ graphene oxide nanocomposite and ionic liquids for fabrication of high sensitive voltammetric sensor on sulfamethoxazole analysis, J. Mol. Liq. 220 (2016) 329.

[8] D.L.C. Golinelli, S.A.S. Machado, I. Cesarino, Synthesis of silver nanoparticle-graphene composites for Electroanalysis applications using chemical and electrochemical methods, Electroanalysis 29 (2017) 1014.

[9] I. Cesarino, R.P. Simões, F.C. Lavarda, A. Batagin-Netoc, Electrochemical oxidation of sulfamethazine on a glassy carbon electrode modified with graphene and gold nanoparticles, Electrochim. Acta 192 (2016) 8.

[10] J. Li, D. Kuang, Y. Feng, F. Zhang, Z. Xu, M. Liu, D. Wang, Green synthesis of silver 
nanoparticles-graphene oxide nanocomposite and its application in electrochemical sensing oftryptophan, Biosens. Bioelectron. 42 (2013) 198.

[11] T. Wen, C. Xue, Y. Li, Y. Wang, R. Wang, J. Hong, X. Zhou, H. Jiang, Reduced graphene oxide-platinum nanoparticles composites based imprinting sensor for sensitively electrochemical analysis of $17 \beta$-estradiol, J. Electroanal. Chem. 682 (2012) 121.

[12] G. Yang, Y. Yang, Y. Wang, L. Yu, D. Zhou, J. Jia, Controlled electrochemical behavior of indium tin oxide electrode modified with Pd nanoparticles via electrospinning followed by calcination toward nitrite ions, Electrochim. Acta 78 (2012) 200.

[13] B. Huang, W.D. Zhang, C.H. Chen, Y.X. Yu, Electrochemical determination of methyl parathion at a Pd/MWCNTs-modified electrode, Microchim. Acta 171 (2010) 57.

[14] F.C. Moraes, I. Cesarino, V. Cesarino, L.H. Mascaro, S.A.S. Machado, Carbon nanotubes modified with antimony nanoparticles: a novel material for electrochemical sensing, Electrochim. Acta 85 (2012) 560.

[15] I. Cesarino, V. Cesarino, M.R.V. Lanza, Carbon nanotubes modified with antimony nanoparticles in a paraffin composite electrode: simultaneous determination of sulfamethoxazole and trimethoprim, Sensors Actuators B Chem. 188 (2013) 1293.

[16] A.M. Ashrafi, S. Cerovac, S. Mudrić, V. Guzsvány, L. Husáková, I. Urbanová, K. Vytřas, Antimony nanoparticle-multiwalled carbon nanotubes composite immobilized at carbon paste electrode for determination of trace heavy metals, Sensors Actuators B Chem. 191 (2014) 320.

[17] I. Cesarino, H.V. Galesco, S.A.S. Machado, Determination of serotonin on platinum electrode modified with carbon nanotubes/polypyrrole/silver nanoparticles nanohybrid, Mater. Sci. Eng. C 40 (2014) 49.

[18] I. Cesarino, V. Cesarino, F.C. Moraes, T.C.R. Ferreira, M.R.V. Lanza, L.H. Mascaro, S.A.S. Machado, Electrochemical degradation of benzene in natural water using silver nanoparticle-decorated carbon nanotubes, Mater. Chem. Phys. 141 (2013) 304.

[19] S.U. Karabiberoglu, E.M. Ayan, Z. Dursun, Electroanalysis of caffeic acid in red wine and investigation of thermodynamic parameters using an Ag nanoparticles modified poly(Thiophene) film glassy carbon electrode, Electroanalysis 25 (2013) 1933.

[20] S. Shahrokhian, S. Rastgar, Electrochemical deposition of gold nanoparticles on carbon nanotube coated glassy carbon electrode for the improved sensing of tinidazole, Electrochim. Acta 78 (2012) 422.

[21] W. Zhu, T. Chen, X. Ma, H. Ma, S. Chen, Highly sensitive and selective detection of dopamine based on hollow gold nanoparticles-graphene nanocomposite modified electrode, Colloids Surf., B 111 (2013) 321.

[22] V. Cesarino, I. Cesarino, F.C. Moraes, S.A.S. Machado, L.H. Mascaro, Carbon nanotubes modified with $\mathrm{SnO}_{2}$ rods for levofloxacin detection, J. Braz. Chem. Soc. 25 (2014) 502.

[23] I. Cesarino, I.A. Hümmelgen, An additional tool towards overcoming absence of specificity of carbon nanostructure-based electrochemical sensors application to estriol and estradiol detection and distinction, J. Solid State Electrochem. 19 (2015) 3045.

[24] D. Liu, L. Li, T. You, Superior catalytic performances of platinum nanoparticles loaded nitrogen-doped graphene toward methanol oxidation and hydrogen evolution reaction, J. Colloid Interface Sci. 487 (2017) 330.

[25] R. de Lima, A.B. Seabra, N. Duran, Silver nanoparticles: a brief review of cytotoxicity and genotoxicity of chemically and biogenically synthesized nanoparticles, J. Appl. Toxicol. 32 (2012) 867.

[26] H. Korbekandi, S. Iravani, The Delivery of Nanoparticles, (2012) Abbass A. Hashim https://doi.org/10.5772/34157.

[27] S. Ferraris, M. Miola, A. Cochis, B. Azzimonti, L. Rimondini, E. Prenesti, E. Vernè, In situ reduction of antibacterial silver ions to metallic silver nanoparticles on bioactive glasses functionalized with polyphenols, Appl. Surf. Sci. 396 (2017) 461.

[28] K. Liu, S. Qu, X. Zhang, F. Tan, Z. Wang, Improved photovoltaic performance of silicon nanowire/organic hybrid solar cells by incorporating silver nanoparticles, Nanoscale Res. Lett. 8 (2013) 1.

[29] T. Yoshimoto, F. Nagai, J. Fujimoto, K. Watanabe, H. Mizukoshi, T. Makino, K. Kimura, H. Saino, H. Sawada, H. Omura, Degradation of estrogens by Rhodococcus zopfii and Rhodococcus equi isolates from activated sludge in wastewater treatment plants, Appl. Environ. Microbiol. 70 (2004) 5283.

[30] F.H. Cincotto, T.C. Canevaric, S.A.S. Machado, A. Sáncheza, M.A.R. Barrioa,
R. Villalongaa, J.M. Pingarróna, Reduced graphene oxide- $\mathrm{Sb}_{2} \mathrm{O}_{5}$ hybrid nanomaterial for the design of a laccase-based amperometric biosensor for estriol, Electrochim. Acta 174 (2015) 332.

[31] C. Oliveira, D.L.D. Lima, C.P. Silva, M. Otero, V.I. Esteves, Photodegradation behaviour of estriol: an insight on natural aquatic organic matter influence, Chemosphere 159 (2016) 545.

[32] L.M. Ochiai, D. Agustinia, L.C.S. Figueiredo-Filho, C.E. Banksc, L.H. MarcolinoJuniora, M.F. Bergaminia, Electroanalytical thread-device for estriol determination using screen-printed carbon electrodes modified with carbon nanotubes, Sensors Actuators B 241 (2017) 978.

[33] K.D. Santos, O.C. Braga, I.C. Vieira, A. Spinelli, Electroanalytical determination of estriol hormone using a boron-doped diamond electrode, Talanta 80 (2010) 1999.

[34] A.P. Fonseca, D.L.D. Lima, V.I. Esteves, Degradation by solar radiation of estrogenic hormones monitored by UV-visible spectroscopy and capillary electrophoresis, Water Air Soil Pollut. 215 (2011) 441.

[35] Z. Li, S. Wang, N.A. Lee, R.D. Allan, I.R. Kennedy, Development of a solid-phase extraction enzyme-linked immunosorbent assay method for the determination of estrone in water, Anal. Chim. Acta 503 (2004) 171.

[36] S. Studzinska, B. Buszewski, Fast method for the resolution and determination of sex steroids in urine, J. Chromatogr. B 927 (2013) 158.

[37] X. Lin, Y. Li, A sensitive determination of estrogens with a Pt nano-clusters/multiwalled carbon nanotubes modified glassy carbon electrode, Biosens. Bioelectron. 22 (2006) 253.

[38] A.R. Allouche, Gabedit-A graphical user interface for computational chemistry softwares, J. Comput. Chem. 32 (2011) 174.

[39] J.J.P. Stewart, MOPAC: A semiempirical molecular orbital program, J. Comput. Aided Mol. Des. 4 (1990) 101.

[40] M.J. Frisch, G.W. Trucks, H.B. Schlegel, G.E. Scuseria, M.A. Robb, J.R. Cheeseman, Gaussian 09, revision D. 01 [Internet], Gaussian, Inc., Wallingford CT, 2009 [cited 2017 Mar 13]. Available from: http://scholar.google.com/scholar?cluster= $12649774174384111814 \&$ hl $=$ en\&oi $=$ scholarr

[41] N. Laube, B. Mohr, A.J. Hesse, Laser-probe-based investigation of the evolution of particle size distributions of calcium oxalate particles formed in artificial urines, J. Cryst. Growth 233 (2001) 367.

[42] E.V. Rokhina, R.P.S. Suri, Application of density functional theory (DFT) to study the properties and degradation of natural estrogen hormones with chemical oxidizers, Sci. Total Environ. 280 (2012) 417-418.

[43] A. Cherkasov, F. Ban, O. Santos-Filho, N. Thorsteinson, M. Fallahi, G.L. Hammond, An updated steroid benchmark set and its application in the discovery of novel nanomolar ligands of sex hormone-binding globulin, J. Med. Chem. 51 (2008) 2047.

[44] R. Garg, N.K. Dutta, N.R. Choudhury, Work function engineering of graphene, Nano 4 (2014) 267.

[45] K.Z. Kamali, A. Pandikumar, G. Sivaraman, H.N. Lim, S.P. Wren, T. Sun, Silver@ graphene oxide nanocomposite-based optical sensor platform for biomolecules, RSC Adv. 5 (2015) 17809.

[46] T.W. Kang, Y.J. Noh, S.S. Kim, H.I. Joh, S.I. Na, Efficient inverted-structure polymer solar cells with reduced graphene oxide for anode modification, J. Ind. Eng. Chem. 24 (2015) 206.

[47] S. Karna, M. Mahat, T.Y. Choi, R. Shimada, Z. Wang, A. Neogi, Competition between resonant plasmonic coupling and electrostatic interaction in reduced graphene oxide quantum dots, Sci Rep. (2016) 36898 Nov 6.

[48] L.M. Ochiai, D. Agustini, L.C.S. Figueiredo-Filho, C.E. Banks, L.H. Marcolino-Junior, M.F. Bergamini, Electroanalytical thread-device for estriol determination using screen-printed carbon electrodes modified with carbon nanotubes, Sensors Actuators B Chem. 241 (2017) 978.

[49] J.P. Silveira, J.V. Piovesan, A. Spinelli, Carbon paste electrode modified with ferrimagnetic nanoparticles for voltammetric detection of the hormone estriol, Microchem. J. 133 (2017) 22.

[50] K.D. Santos, O.C. Braga, I.C. Vieira, A. Spinelli, Electroanalytical determination of estriol hormone using a boron-doped diamond electrode, Talanta 80 (2010) 1999.

[51] S.H. Wang, S.L. Lin, L.Y. Du, H.S. Zhuang, Electrochemical enzyme-linked immunoassay for the determination of estriol using methyl red as substrate, Anal. Lett. 39 (2006) 947. 